\title{
INTEGRATED MICRO WOBBE INDEX METER TOWARDS ON-CHIP ENERGY CONTENT MEASUREMENT J.C. Lötters ${ }^{1,2}$, T.S.J. Lammerink ${ }^{2}$, M.G. Pap ${ }^{2}$, R.G.P. Sanders ${ }^{2}$ M.J. de Boer ${ }^{2}$, A.J. Mouris ${ }^{3}$ and R.J. Wiegerink ${ }^{2}$ \\ ${ }^{1}$ Bronkhorst High-Tech BV, The Netherlands, ${ }^{2}$ MESA+ Institute for Nanotechnology, University of Twente, The Netherlands, ${ }^{3}$ Hobré Instruments BV, The Netherlands
}

\begin{abstract}
In this paper, the first step towards an on-chip energy content measurement system is presented. The system comprises an integrated micro Wobbe index meter, consisting of 2 gas inlets, a mixer, a combustion chamber, heaters, temperature sensors and an exhaust outlet. With an integrated micro Wobbe meter, the energy content of natural gas, biogas, hydrogen and other fuel gases can be measured accurately, in-line, real-time and with very little gas consumption. First measurement results have indicated the feasibility of the concept.
\end{abstract}

\section{INTRODUCTION}

It is expected that the composition and quality of the natural gas in national gas grids is going to vary enormously due to the blending of natural gas from different countries, the addition of biogas and periodical variations in both gas types. Moreover, the introduction of biogas in national gas grids is hindered by the absence of a cheap, reliable and miniature device for the energy content measurement of fuel gases. The integrated micro Wobbe index meter will provide a point-of-use solution for these and other applications, e.g. burner control, where constant gas quality is required.

At the moment, only conventional, large and expensive equipment exists, e.g. a Wobbe index meter [1] or a gas chromatograph [2]. Although a basic concept has been disclosed [3] that is totally different to our concept, to our knowledge never before measurement results of an on-chip energy content meter have been published.

In this paper, we will first explain and define the Wobbe index, and present a schematic diagram of the final complete on-chip energy content measurement system. Subsequently, we will present the initial basic structure and operating principle, design and fabrication, and first measurement results of the integrated micro Wobbe index meter.

\section{WOBBE INDEX}

The Wobbe Index $W I\left[\mathrm{MJ} / \mathrm{Nm}^{3}\right]$, named after Italian engineer and mathematician Goffredo Wobbe, is used to compare the combustion energy output for fuel gases with different compositions, and can be calculated with [1]:

$$
W I=\frac{H}{\sqrt{G_{s}}}
$$

where $H\left[\mathrm{MJ} / \mathrm{Nm}^{3}\right]$ is the amount of heat generated by the complete combustion of a certain volume of fuel gas with air; and $G_{s}[-]$ is the ratio of the mass densities of fuel gas and air.

\section{SYSTEM DESIGN}

In figure 1, a schematic design of the envisioned energy content measurement system is shown. The system can be integrated on a silicon chip with dimensions of the order of $2 \mathrm{~cm} \times 2 \mathrm{~cm}$. At the fuel gas and air inlets it has micro Coriolis mass flow meters [4] that measure both the mass flow and density. Next, the fuel gas and air are pre-heated up to a temperature of $600{ }^{\circ} \mathrm{C}$ in separate tubes. Integrated silicon nitride tubes are used, which can withstand temperatures up to approximately $1000{ }^{\circ} \mathrm{C}$, which is the deposition temperature of silicon nitride. On a thermally insulated part of the chip, the fuel gas and air are mixed and the elevated temperature is sufficient for spontaneous combustion of the fuel gas. The produced heat will result in a further elevation of temperature, which is dependent on the thermal conduction towards the silicon substrate and is a measure for the energy content of the fuel gas.

A careful design is needed such that the maximum temperature for the silicon nitride tubes is not exceeded. Optionally, a catalyst may be introduced in the tubes, which significantly complicates the fabrication process, but also lowers the temperature needed for spontaneous combustion to about $300{ }^{\circ} \mathrm{C}$. The temperature sensors needed for measuring the amount of temperature elevation are located at a certain distance from the reaction chamber where the temperature is lower.

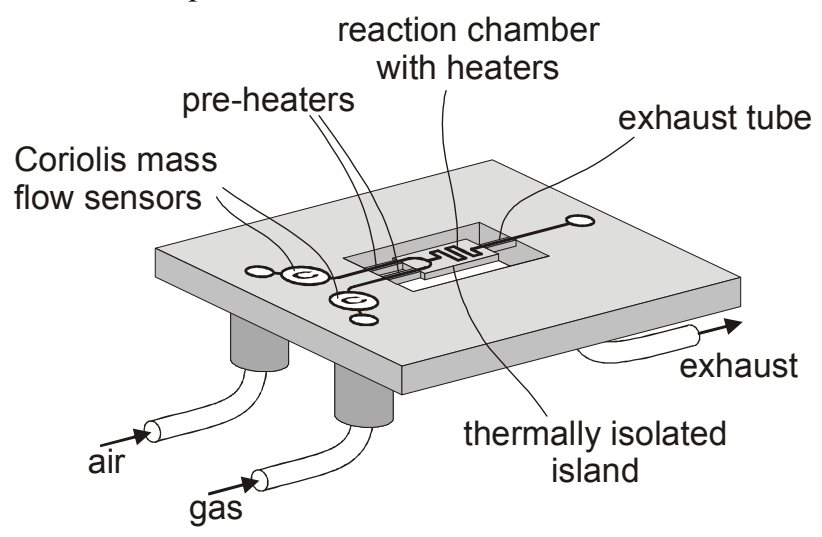

Figure 1: Schematic design of the envisioned on-chip energy content measurement system.

\section{INITIAL DESIGN}

The initial design of the integrated micro Wobbe index meter is shown in figure 2 . The system consists of 2 gas inlets, a mixer, a combustion chamber, heaters, temperature sensors and an exhaust gas outlet. It should be noted that the micro Coriolis mass flow meters have not been incorporated in this initial design. 

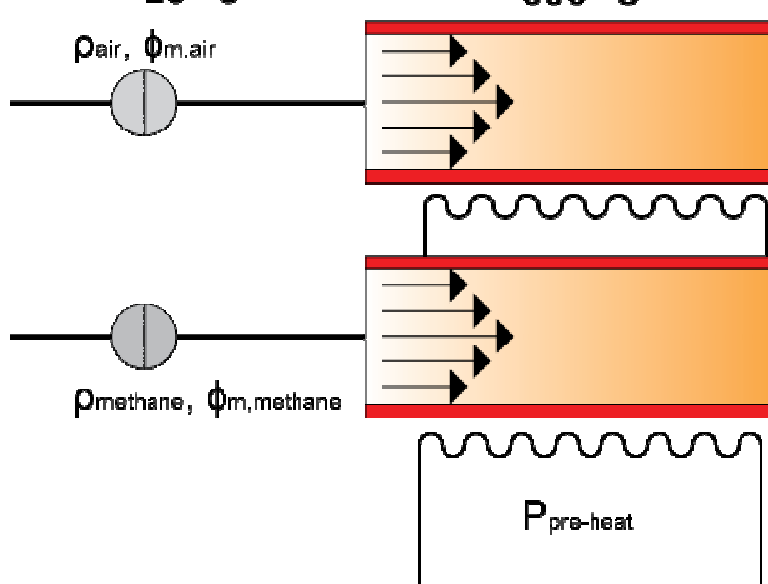

Figure 2: Initial design of the integrated micro Wobbe index meter

\section{OPERATING PRINCIPLE}

Fuel gas and air are flowing at ambient temperature into the chip through external flow sensors. Next, both fuel gas and air are heated up to $600{ }^{\circ} \mathrm{C}$ by using resistive heaters. The fuel gas and air streams are then mixed in a thermally insulated part of the chip, as shown in figure 3, resulting in spontaneous combustion. The resulting elevation in temperature, which can be measured using integrated platinum resistors, is a measure for the amount of heat generated by the combustion of the fuel gas.

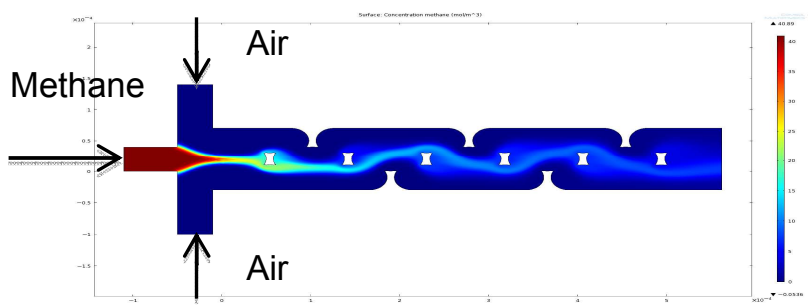

Figure 3: simulation results of the mixer when mixing methane and air

\section{FABRICATION}

The device as shown in figure 4 has been realised applying similar technology as used for the micro Coriolis flow sensors [4], which provides the opportunity to integrate micro Coriolis flow sensors in the system as well.

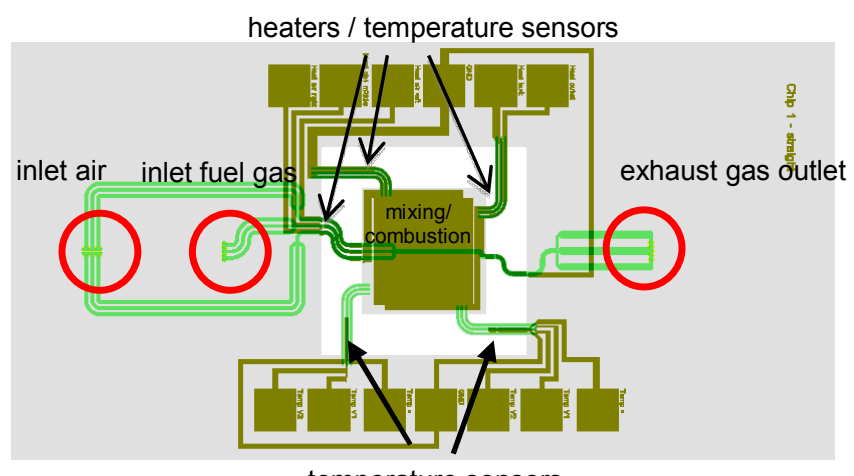

temperature sensors

Figure 4: Mask lay-out of the integrated Wobbe index meter

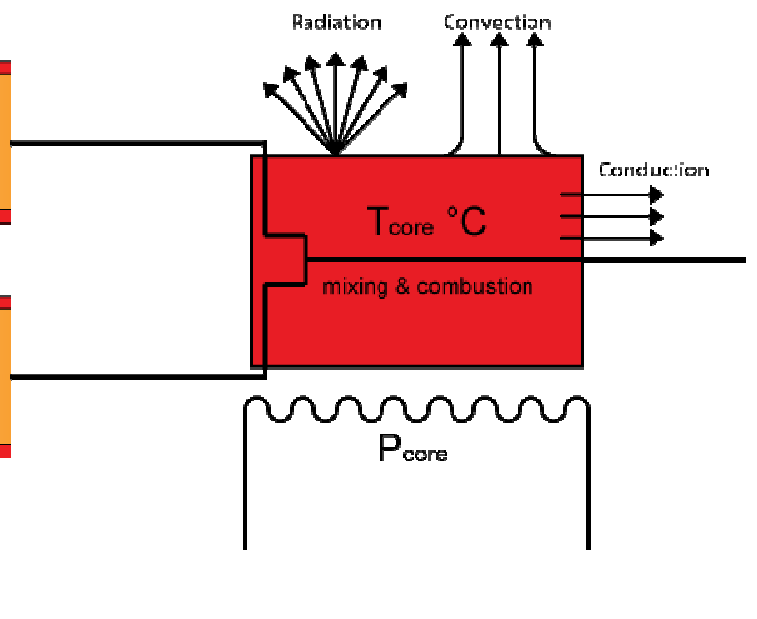

1

2

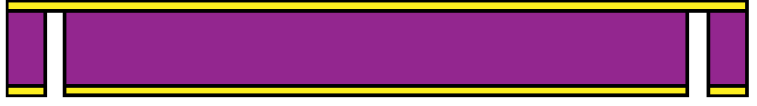

3

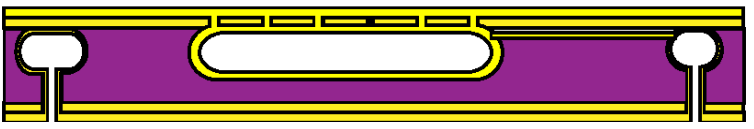

4

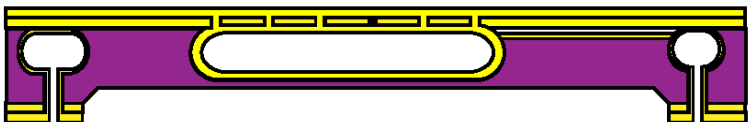

5

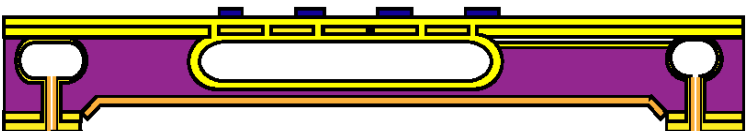

6
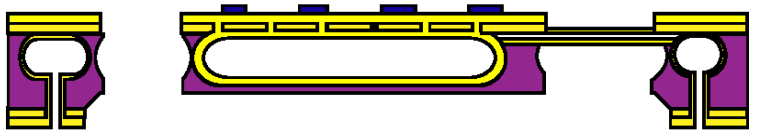

Silicon

SiRN

Platinum

TEOS

Figure 5. Fabrication process; (1) bare $<100>$ wafer;

(2) access holes to the channels; (3) creating the channels;

(4) back-etch of the thermally insulated core;

(5) heaters; (6) isolation of the core

The fabrication process, as shown in figure 5 , starts with a bare double side polished $<100\rangle$ wafer with a thickness of $385 \mu \mathrm{m}$. First, a 500nm thick low-stress silicon-rich silicon nitride (SiRN) layer is grown by LPCVD. Next, the pattern for the access-holes is created at the backside of the wafer (Figure 5, step 2) by deep reactive ion etching (DRIE). A $5.2 \mu \mathrm{m}$ think layer of SU8-2005 photoresist is used as etch mask. 
Next, the access-holes are covered with a $1100 \mathrm{~nm}$ layer of TEOS to prevent wafer-through holes while etching the channels at the front side of the wafer. The TEOS layer at the front side of the wafer is removed with BHF while the backside is protected by dicing foil. Next, the channels at the front side are created by isotropic etching of silicon through narrow slits in the top silicon nitride layer. The TEOS is removed so that there is an open connection between the front- and backside of the wafer and a layer of $\mathrm{SiRN}$ is grown inside the channels, closing the etch slits in the top of the channels (Figure 5, step 3).

$\mathrm{Next}, \mathrm{KOH}$ etching from the backside is used to define the thickness of the thermally insulated core which contains the reaction chamber. Dupont MX5020 foil is used as masking layer. The reason to use this foil was that it provides a simple way to close the access holes to the channels which are already present. The foil is used for etching the SiRN layer, which then forms the etch mask during $\mathrm{KOH}$ etching. Etching is stopped when the desired depth is reached (Figure 5, step 4).

Next, the etched silicon surface is covered by growing an $1100 \mathrm{~nm}$ thick layer of TEOS which will later serve as etch-stop during the final release etch where it will also provide additional rigidity and thermal conductivity. The TEOS is removed from the front side of the wafer and a layer of platinum is deposited, patterned, oxidized and etched (Figure 5, step 5).

Finally, the SiRN layer at the front side is patterned and the thermally insulated core is released with semi-isotropic etching to completely underetch the inlet and exhaust channels. The etching stops at the TEOS layer. Finally, the TEOS layer is removed and the wafer is broken into separate chips along breaking grooves etched during the $\mathrm{KOH}$ etch step (Figure 5, step 6). The fabricated Wobbe index meter is shown in figure 6 .

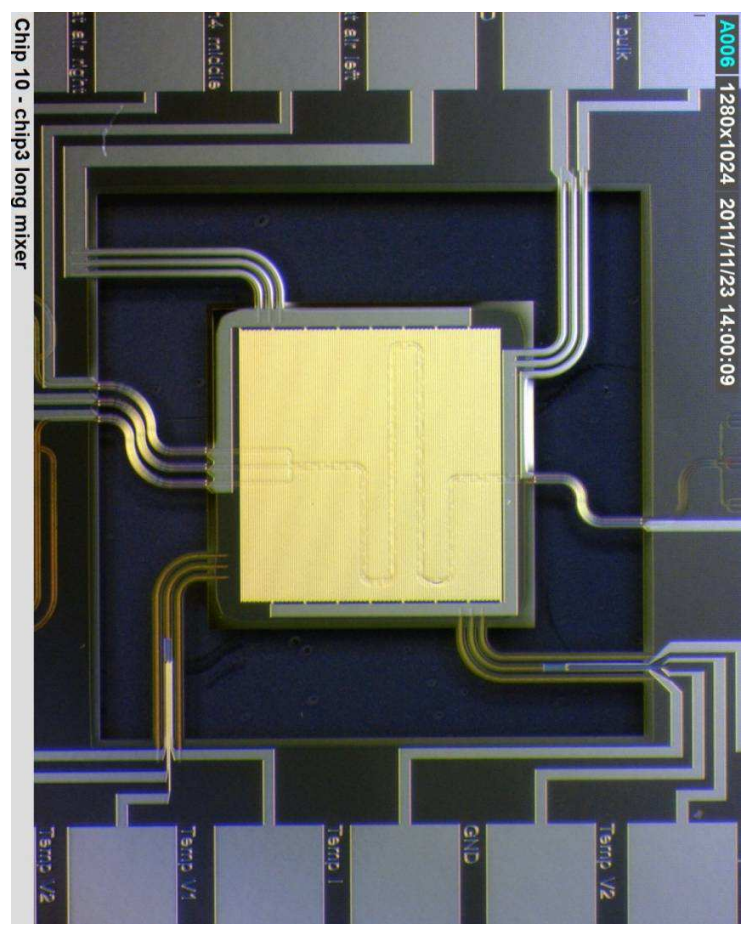

Figure 6: Fabricated Wobbe index meter according to the mask layout of figure 4 and the process steps of figure 5
MEASUREMENT SET-UP

The measurement set-up is shown in figure 7.

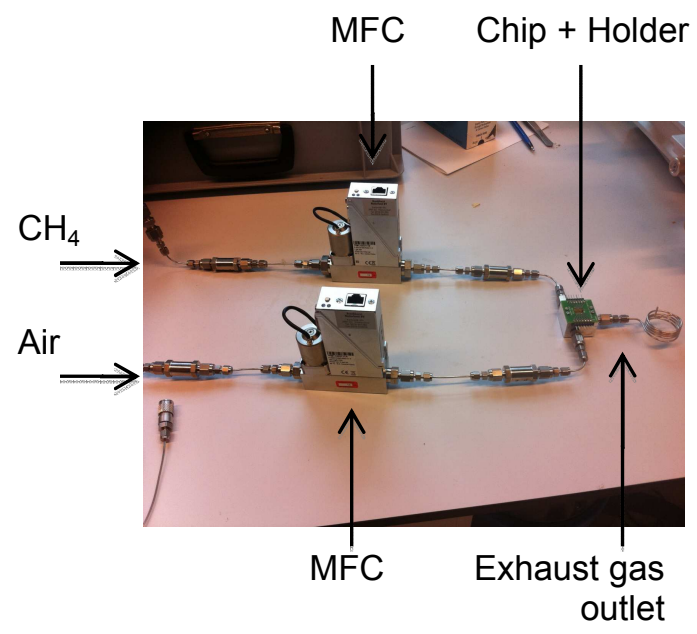

Figure 7. Measurement set-up

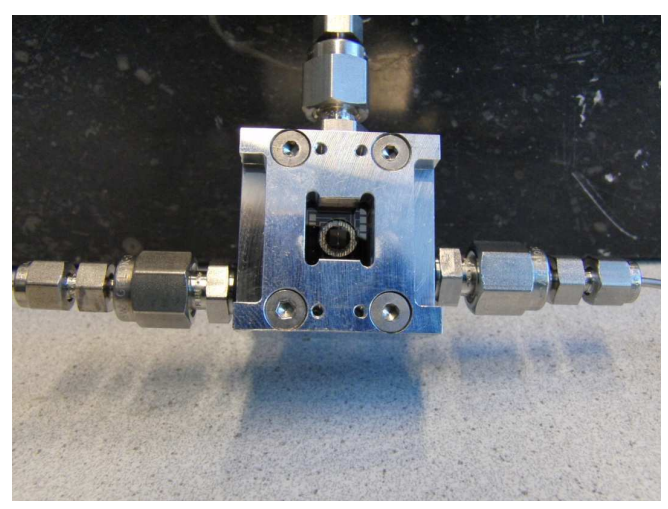

Figure 8. Close-up of chip in holder

Flow of methane gas and air is controlled by two mass flow controllers (MFCs). Both gases are flowing at ambient temperature into the chip, which is placed in a holder (figure 8). In the chip, both gases are pre-heated up to $600{ }^{\circ} \mathrm{C}$ by using resistive heaters. The methane gas and air flows are then mixed and further heated, partly by external heaters, in a thermally insulated part of the chip resulting in spontaneous combustion. The resulting elevation in temperature, which is measured with integrated platinum resistors, is a measure for the amount of heat generated by the combustion of the methane gas. Finally, the gas leaves the chip via the exhaust gas outlet.

\section{MEASUREMENT RESULTS}

Measurement results obtained with the integrated micro Wobbe index meter are shown in figure 9.

Flow pulses with a duration of $10 \mathrm{~s}$ of $150 \mathrm{mg} / \mathrm{h}$ methane gas and $1300 \mathrm{mg} / \mathrm{h}$ air were simultaneously provided to the respective gas inlets of the system, with a time interval of $90 \mathrm{~s}$ in between pulses. As can be seen in figure 9, during a flow pulse spontaneous combustion of the mixture of methane and air occurs, as shown by the temperature rise from $440{ }^{\circ} \mathrm{C}$ to $460{ }^{\circ} \mathrm{C}$ indicated by the temperature sensors. The temperature is lower than $600{ }^{\circ} \mathrm{C}$ due to the location of the temperature sensors, which have been placed deliberately away from the hottest areas. 


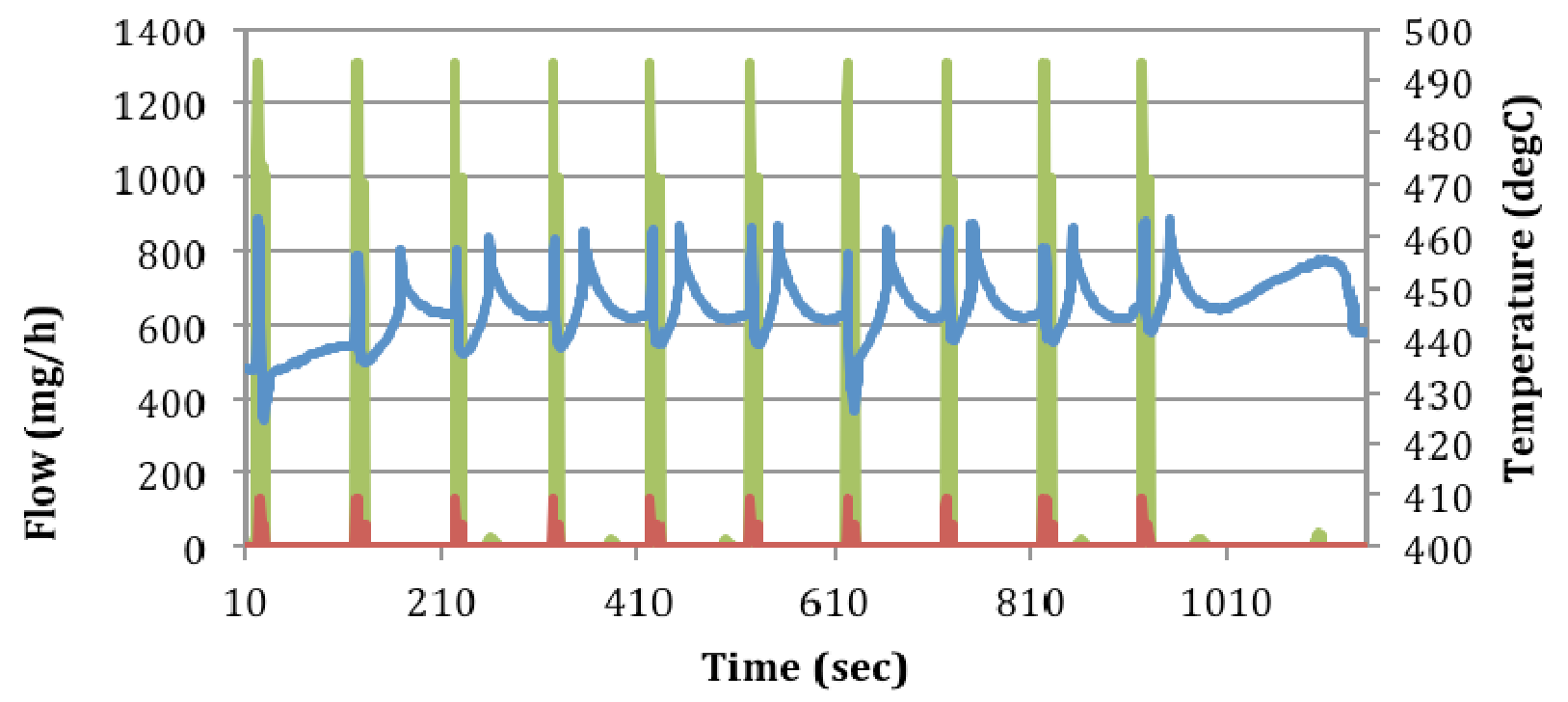

Air flow $(\mathrm{mg} / \mathrm{h}) \quad \mathrm{CH} 4$ flow $(\mathrm{mg} / \mathrm{h}) \quad$ Tbeam $(\mathrm{degC})$

Figure 9. Measurement results. Flow pulses of methane and air are provided to the Wobbe meter. Periodical temperature elevations from $440{ }^{\circ} \mathrm{C}$ to $460{ }^{\circ} \mathrm{C}$ can be observed due to spontaneous combustion of the air / methane mixture

In the time interval that no flow pulse is provided to the system, another temperature rise can be seen, which can be explained by spontaneous combustion of the remainder of the methane gas, which was still in the system.

\section{CONCLUSIONS}

We designed, fabricated and characterised an integrated micro Wobbe index meter for the energy content measurement of fuel gases such as natural gas, biogas and hydrogen. The micro Wobbe index meter consists of 2 gas inlets, a mixer, a combustion chamber, heaters, temperature sensors and an exhaust outlet. First measurement results have indicated the feasibility of the concept by on-chip spontaneous combustion of methane gas.

\section{FUTURE WORK}

Further research will focus on the integration of the micro Coriolis mass flow meters, realisation of a mixing / combustion chamber for continuous combustion, and catalytic combustion at lower temperatures.

\section{ACKNOWLEDGEMENTS}

The authors would like to thank Bronkhorst High-Tech BV and Hobré Instruments BV from The Netherlands for financially supporting this project.

\section{REFERENCES}

[1] A.J. Mouris, Optimized fired heater control, Hydrocarbon Processing, November 2010, pp. 65 - 68

[2] P. Ulbig, D. Hoburg, Determination of the calorific value of natural gas by different methods, Thermochimica Acta, 382 (2002), pp. 27 - 35

[3] J. Bats, F.J.J. Huijsmans, Apparatus and method for determining stoichiometric molar flow ratio for oxidation of a fuel, Patent GB2474570B, June 2012

[4] J. Haneveld, T.S.J. Lammerink, M.J. de Boer, R.G.P. Sanders, A. Mehendale, J.C. Lötters, M. Dijkstra, R.J. Wiegerink, Modeling, design, fabrication and characterization of a micro Coriolis mass flow sensor, J. Micromech. Microeng., 20 (2010), 125001, pp. $1-10$.

\section{CONTACT}

*J.C. Lötters, tel:: +31-573-458800; j.c.lotters@bronkhorst.com 